\title{
AVALIAÇÃo do POTENCIAL DE PRODUÇÃO DE SEDIMENTOS EM UMA BACIA HIDROGRÁFICA DO OESTE CATARINENSE
}

\author{
Tainá Braúlio HENNIG ${ }^{1}$ \\ Aline de Almeida MOTA²
}

\section{Resumo}

Este estudo teve como objetivo avaliar o potencial atual de produção de sedimentos da bacia hidrográfica do Lajeado São José, principal manancial de abastecimento de Chapecó-SC, e a influência em um horizonte de 30 anos de alterações no uso do solo da bacia permitidas pelas diretrizes do Plano Diretor do Município de Chapecó na produção de sedimento por meio da aplicação da USLE (Universal Soil Loss Equation). A produção potencial de sedimentos para as condições de uso e cobertura do solo atuais variou, na área da bacia, entre 0 e 30,2 t.ha- ${ }^{-1}$. mês ${ }^{-1}$, apresentando uma taxa erosiva de 3,88 t.ha- ${ }^{-1}$.ano-1 utilizando o método de obtenção de $C$ a partir do NDVI, enquanto pelo método de valores tabelados na literatura, a produção de sedimentos variou entre 0 e 26,6 t.ha ${ }^{-1}$. $\mathrm{mês}^{-1}$, sendo a média 2,41 t.ha ${ }^{-1}$. ano ${ }^{-1}$. Considerando a tendência de urbanização da bacia, a previsão é que daqui a 30 anos a taxa chegue a 2,26 t.ha $^{-1}$.ano ${ }^{-1}$. A redução de $6,2 \%$ na taxa média anual ocorre, principalmente, pois atualmente o principal uso do solo da bacia é agrícola, e no processo de urbanização seria substituído por área urbana, que tem valor de $C$ menor devido à impermeabilização diminuir a exposição do solo à erosão.

Palavras-chave: USLE. Erosão. Hidrossedimentologia. Uso do solo.

\section{Abstract \\ Assessment of potential sediment production in a basin in western Santa Catarina, Brazil}

The objective of this study was to evaluate the current sediment potential yield of the Lajeado São José basin, the main source of water supply for Chapecó-SC, and the influence of 30-year changes in basin soil use that are allowed by the guidelines of the Master Plan of the Municipality of Chapecó in the production of sediment through the application of USLE (Universal Soil LoSS Equation). Potential sediment yields for current soil use and cover conditions varied between 0 and 30.2 t.ha $^{-1} \cdot$ month $^{-1}$ in the area of the basin, presenting an erosive rate of 3.88 t. ha $^{-1}$.year-1 by using the method of $C$ derived from the NDVI, while by the method of $C$ from literature, the production of sediments varied between 0 and 26.6 t. ha $^{-1}$. month ${ }^{-1}$, the average being of 2.41 t.ha $^{-1}$.year-1. Considering the trend of urbanization of the basin, the forecast is that in 30 years the rate will reach 2.26 t.ha $^{-1}$.year ${ }^{-1}$. The reduction of $6.2 \%$ in the annual average rate occurs mainly because currently the main soil use of the basin is agricultural, and in the process of urbanization would be replaced by urban area, which has a lower $C$ value due to the impermeabilization that decreases the exposure of the soil to erosion.

Key words: USLE. Erosion. Hydro-sedimentology. Soil use.

\footnotetext{
1 Acadêmica do curso de Bacharelado em Engenharia Ambiental e Sanitária pela Universidade Federal da Fronteira Sul; Rua Rudolfo Zwick, no 129, Bairro Bela Vista, Palmitos-SC, CEP: 89887-000. E-mail: hennigtain@gmail.com

2 Professora do curso de Engenharia Ambiental e Sanitária, Universidade Federal da Fronteira Sul - Campus Chapecó; Av. Fernando Machado, 108 E, Centro, Chapecó, SC, Brasil, Caixa Postal 181, CEP 89802-112. E-mail: aline.mota@uffs.edu.br
} 


\section{INTRODUÇÃO}

O ciclo hidrossedimentológico acontece na fase terrestre do ciclo hidrológico, e consiste nas dinâmicas que relacionam os sedimentos e a água. Tucci (1993) afirma que o ciclo hidrossedimentológico é totalmente dependente do ciclo hidrológico, uma vez que neste são envolvidos os processos de erosão, transporte e deposição das partículas de solo que estão presentes na superfície da bacia hidrográfica. Considerando a dinâmica do ciclo hidrossedimentológico, tem-se como evidência que a maior parte das partículas de solo é desprendida na área das cabeceiras da bacia, uma vez que estes locais são compostos, geralmente, por encostas mais declivosas. Este ciclo acontece naturalmente, porém pode ser acelerado por conta de ações antrópicas bem como alterações no uso do solo, acarretando em aumento na produção de sedimentos (CUNHA; MENDES; SANCHEZ, 1999; OLIVEIRA; PINTO, 2003).

Sabendo dos danos causados por processos erosivos em atividades econômicas que envolvem a agricultura, meio ambiente e também a infraestrutura e drenagem no meio urbano é possível relacionar tal fenômeno com perdas de ordem financeira, material e ambiental.

A erosão tem sido amplamente estudada em virtude de suas consequências, mas os problemas de cunho ambiental relacionados à erosão, o transporte e a deposição de sedimentos é que têm alavancado o desenvolvimento de estudos na área. Do ponto de vista ambiental, Carvalho (2008) cita diversos impactos negativos que ocorrem por conta da presença excessiva de sedimentos nos ecossistemas aquáticos, como a piora da qualidade da água já que os sedimentos podem atuar como portadores de uma série de poluentes; a diminuição de atividades relacionadas à fotossíntese, já que ocorre aumento significativo na turbidez do corpo d'água; além das alterações que acontecem na biota aquática. Ainda, podem ocorrer processos de assoreamento, fazendo com que se tenha uma diminuição da vida útil de reservatórios artificiais.

Neste contexto, Bellinaso e Paiva (2007) refletem que no que tange à gestão de recursos hídricos, é fundamental conhecer a produção de sedimentos em bacias hidrográficas.

Existem diversas maneiras para se estimar a produção de sedimentos (MERRITT; LETCHER; JAKEMAN, 2003): modelos empíricos, os quais utilizam relações matemáticas que são baseadas em observações como a MUSLE (Modified Universal Soil Loss Equation) proposta por Williams (1975), por exemplo; ou modelos conceituais, que são baseados em processos físicos observados, os quais procuram descrever todas as etapas que envolvem o fenômeno estudado e que são mais complexos, haja vista a necessidade de maior quantidade de dados de entrada, como o modelo SWAT (Soil and Water Assessment Tool) proposto por Arnold et al. (1998) e AGNPS (Agricultural Non-point Source Pollution Model) proposto por Young et al. (1989). Os modelos conceituais podem ser extremamente caros e difíceis de executar.

A USLE (Universal Soil Loess Equation), que determina a erosão, é um dos modelos empíricos mais aceitos por pesquisadores, além de mais utilizado, apresentando aplicabilidade avançada em diversas partes do mundo (BARBOSA et al., 2015; CORRÊA; PINTO; COUTO JUNIOR, 2015; RISSO et al., 2004; SILVA, 2008; VIEIRA, 2008).

O principal manancial de abastecimento do município de Chapecó-SC é a bacia hidrográfica do Lajeado São José. Em 1990, já havia preocupações quanto à produção de sedimentos e turbidez da água nesta bacia, motivando o trabalho de Bassi (1990). Porém, os fatores que influenciam a erosão estão em constante alteração, especialmente quando se trata de bacias que têm parte de seu território urbanizado, e por este motivo é necessário atualizar as estimativas da produção de sedimentos. 
O Plano Diretor do município (Lei complementar no 541, CHAPECÓ, 2014) foi aprovado recentemente, porém ainda não se sabe quais serão ao certo os impactos que estas diretrizes de ordenamento do uso da terra terão especificamente na produção de sedimentos.

Diante disto, teve-se por objetivo avaliar o potencial atual de produção de sedimentos na bacia hidrográfica do Lajeado São José e a influência de alterações no uso do solo da bacia permitidas pelas diretrizes do Plano Diretor do Município de Chapecó na produção de sedimentos, por meio da aplicação da USLE.

\section{MATERIAL E MÉTODOS}

Área de estudo

Inserida na região hidrográfica do rio Uruguai, com uma área de $76,32 \mathrm{~km}^{2} \mathrm{e}$ perímetro de $64,56 \mathrm{~km}$, a bacia hidrográfica do Lajeado São José está localizada nos municípios de Chapecó (SC) e Cordilheira Alta (SC), região oeste de Santa Catarina (Figura 1).
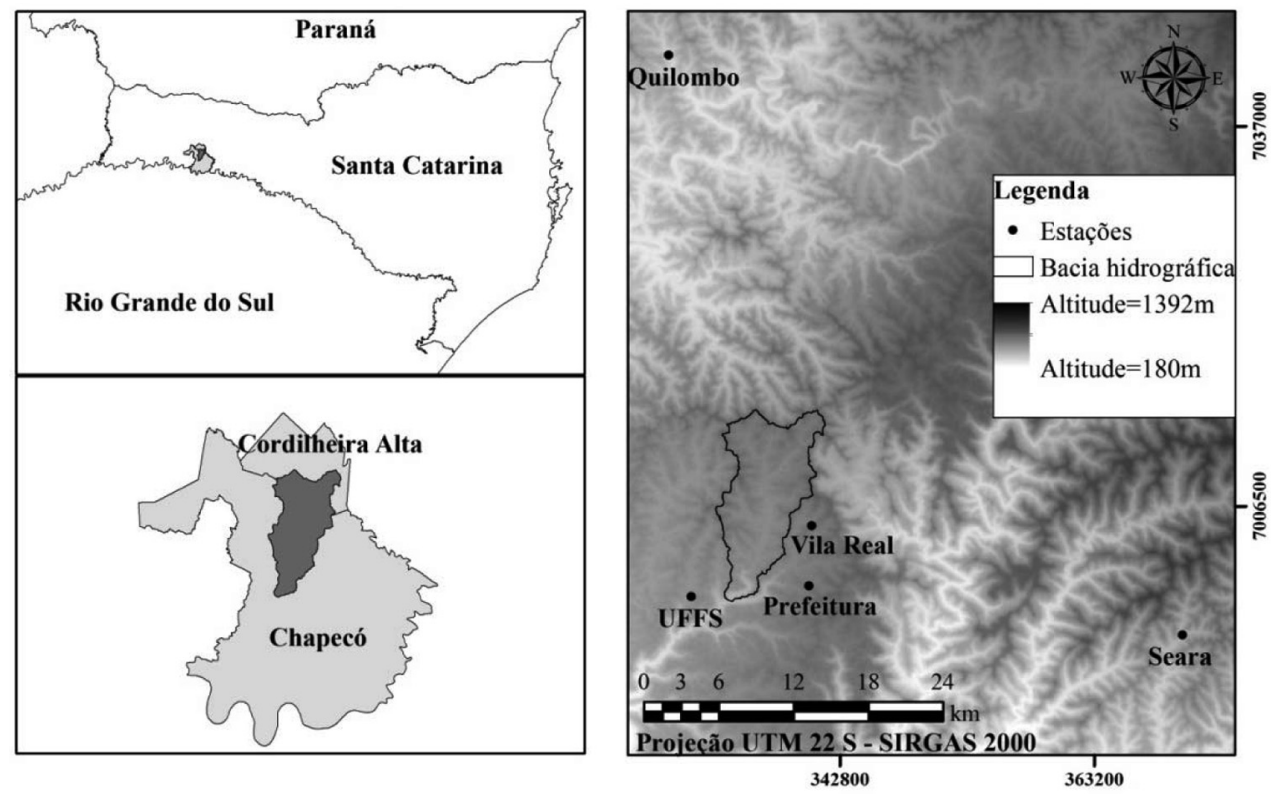

Figura 1 - Localização da bacia hidrográfica do Lajeado São José e das estações pluviométricas das quais os dados foram utilizados

A bacia hidrográfica do Lajeado São José possui formato alongado no sentido Norte-Sul e está inserida entre as altitudes de 805 e 466 m Figura 1). A densidade de drenagem é de $2,89 \mathrm{~km} \cdot \mathrm{km}^{-2}$. Com a utilização do método de Strahler, pode-se cons- 
tatar que a bacia hidrográfica do Lajeado São José é de ordem 4, sendo a escala da base cartográfica 1:50.000. O índice de compacidade da bacia é de 2,08, e fator de forma 0,09.

A principal característica geológica da bacia hidrográfica são os derrames de lavas da formação Serra Geral. O relevo é marcado por ser montanhoso, com morros e montanhas, e também suave-ondulado, composto por tabuleiros, chapadas e superfícies aplainadas (SANTA CATARINA, 1991).

O clima da bacia hidrográfica é classificado como superúmido, sendo influenciado pelas massas de ar frias provenientes da Antártida pelo regime de chuvas e também pelos ventos provenientes do sudeste. A temperatura média anual é de aproximadamente $19{ }^{\circ} \mathrm{C}$. A precipitação média anual é de aproximadamente $2200 \mathrm{~mm}$, com uma umidade relativa anual de aproximadamente $80 \%$ (SANTA CATARINA, 1991).

\section{Produção de sedimentos por processos erosivos}

A produção de sedimentos da bacia hidrográfica do Lajeado São José foi determinada por meio da aplicação de uma modelagem matemática voltada ao fator ambiental: a USLE (equação 1), equação esta proposta por Wischmeier e Smith (1978).

$$
\text { USLE }=\text { R.K.LS.C.P }
$$

Onde: $U S L E=$ estimativa da perda de solo $\left(\right.$ t.ha $\left.{ }^{-1}\right) ; R=$ fator de erosividade da chuva (MJ.mm.ha-1.h-1); $K=$ fator de erodibilidade do solo (t.ha.h.ha-1. $\mathrm{MJ}^{-1} \cdot \mathrm{mm}^{-1}$ ); $L S$ = fator topográfico (adimensional); $C=$ fator de cobertura, uso e manejo do solo (adimensional); $P=$ fator de práticas contra a erosão (adimensional).

O cálculo da USLE foi realizado por meio do uso de um SIG (Sistema de Informações Geográficas), o software ArcGis 10.3.1.

Após a elaboração dos mapas que carregavam os resultados para cada uma das variáveis da equação 1 , a produção de sedimentos foi calculada por meio da multiplicação dos mesmos utilizando a ferramenta "Raster calculator" do ArcGis 10.3.1.

\section{Fator $R$}

O fator $R$ é dado como o índice de erosão provocado pela precipitação. Expressa a capacidade que a chuva apresenta para causar erosão em uma área desprotegida, ou seja, sem cobertura vegetal. Pode ser definido como o produto da energia cinética apresentada por uma precipitação pela intensidade máxima que pode apresentar, em um tempo de 30 minutos (CARVALHO, 2008; HUDSON, 1973; RIGHETTO, 1998).

Para a determinação deste fator foram utilizadas séries de dados referentes a cinco estações pluviométricas localizadas ao redor da bacia hidrográfica do Lajeado São José (Tabela 1 e Figura 1). Todas as estações foram instaladas recentemente, e realizam medições em intervalos de 10 minutos. A estação que possui maior período (15 meses) de monitoramento é a estação da UFFS (Universidade Federal da Fronteira Sul).

Os valores de erosividade variam com os meses, dependendo da ocorrência de precipitações com maiores intensidades. A média mensal é de 13 dias com ocorrência de chuva, porém, existe certa variabilidade ao longo do ano. De acordo com a figura 2, nas estações de Quilombo e Seara foram registrados mais dias com chuva, 199 e 173 no período, respectivamente. 
Tabela 1 - Estações pluviométricas das quais os dados foram obtidos

\begin{tabular}{l|lllll}
\hline Instituição & UFFS & CEMADEN & CEMADEN & CEMADEN & CEMADEN \\
\hline Código & - & $420420201 \mathrm{~A}$ & $420420202 \mathrm{~A}$ & $421420102 \mathrm{~A}$ & $421750101 \mathrm{~A}$ \\
\hline Nome & UFFS & Prefeitura & Vila Real & Quilombo & Seara \\
\hline Altitude $(\mathbf{m})$ & 610 & 724 & 706 & 390 & 525 \\
\hline Longitude* (m) & 330896,96 & 340316,63 & 340536,94 & 329088,625 & 370302,60 \\
\hline Latitude* (m) & 6999242,74 & 7000091,20 & 7004931,85 & 7042709,52 & 6996157,17 \\
\hline $\begin{array}{l}\text { Período de } \\
\text { monitoramento }\end{array}$ & $13 / 03 / 2015$ a & $18 / 08 / 2015$ a & $18 / 08 / 2015$ a & $18 / 08 / 2015$ a & $18 / 08 / 2015$ a \\
\hline $\begin{array}{l}\text { Total precipitado } \\
\text { (mm) }\end{array}$ & $2603 / 05 / 2016$ & $07 / 08 / 2016$ & $07 / 08 / 2016$ & $30 / 08 / 2016$ & $30 / 08 / 2016$ \\
\hline
\end{tabular}

* Coordenadas em SIRGAS 2000, projeção UTM, Fuso 22S.

Os meses com maior volume de precipitações foram novembro e dezembro de 2015. De forma individual, todas as estações apresentaram maior volume de precipitação em algum dos meses citados, exceto a estação de Quilombo, em que o mês com maior precipitação foi em outubro.
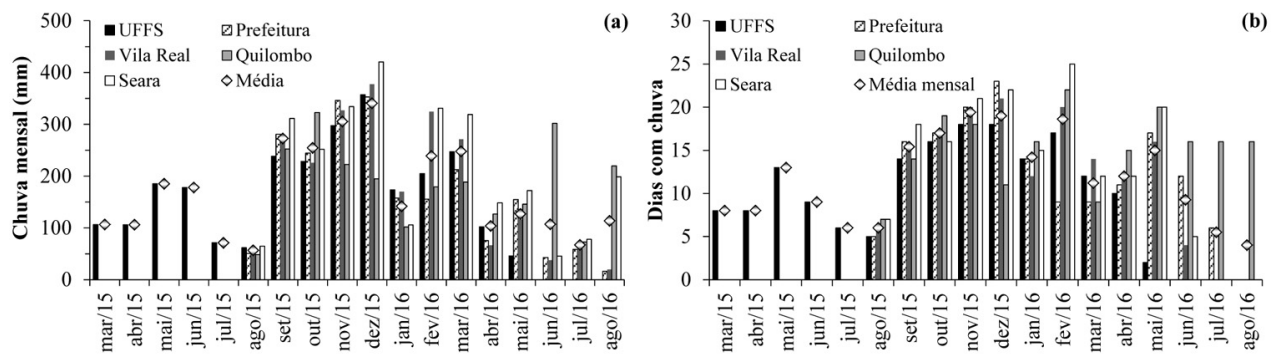

Figura 2 - Características da série de precipitação em cada uma das estações pluviométricas: (a) Chuva mensal; e (b) Número de dias com registros de ocorrências de precipitação

O índice $R$ foi determinado para todas as chuvas erosivas - todo evento de chuva que ocasione lâmina d'água igual ou superior a $10,0 \mathrm{~mm}$, ou com lâmina maior ou igual a $6,0 \mathrm{~mm}$ com duração inferior a 15 minutos (WISCHMEIER, 1959). As chuvas erosivas foram determinadas por meio de programação computacional.

Após a identificação das chuvas erosivas, a energia cinética unitária destas foi determinada. A energia $e_{1}$ pôde ser estimada mediante duas situações: quando $i \leq 76$ $\mathrm{mm} \cdot \mathrm{h}^{-1}$ (equação 2) e quando $i>76 \mathrm{~mm} \cdot \mathrm{h}^{-1}$ (equação 3) (FOSTER et al., 1981).

$$
\begin{gathered}
e_{1}=0,119+0,0873 \cdot \log _{10}(i) \\
e_{1}=0,238
\end{gathered}
$$

Onde: $e_{1}=$ energia cinética unitária $\left(\mathrm{MJ} \cdot \mathrm{ha}^{-1} \cdot \mathrm{mm}^{-1}\right)$. 
Posteriormente, utilizou-se da equação 4 para a determinação da energia $E$.

$$
E=e_{1} \cdot a
$$

Onde: $E$ = energia de determinado evento de chuva $\left(\mathrm{MJ}^{\mathrm{h}} \mathrm{ha}^{-1}\right) ; e_{1}=$ energia cinética unitária $\left(\mathrm{MJ} \cdot \mathrm{ha}^{-1} \cdot \mathrm{mm}^{-1}\right) ; a=$ altura total precipitada $(\mathrm{mm})$.

Por fim, a determinação de $R$ foi efetuada por meio da equação 5, proposta por Bertoni e Lombardi Neto (1985).

$$
R=\sum_{j=1}^{N}\left(E \cdot I_{30}\right)_{j}
$$

Onde: $E$ = energia de determinado evento de chuva $\left(\mathrm{MJ}_{\mathrm{h}} \mathrm{ha}^{-1}\right) ; I_{30}=$ intensidade da chuva média de 30 minutos, e máxima ao longo da duração da chuva $\left(\mathrm{mm} \cdot \mathrm{h}^{-1}\right) ; j=$ evento pluviométrico em um período mensal; $N=$ número de chuvas erosivas ocorridas no período.

A interpolação dos dados de $R$ médio mensal referente a cada estação pluviométrica foi feita por meio da ferramenta "IDW" fazendo com que, além dos pontos que representavam as estações, toda a área da bacia hidrográfica obtivesse um valor de $R$ correspondente. O resultado da interpolação, e deste fator, foi obtido em forma de mapa em formato raster.

\section{Fator $\mathrm{K}$}

De acordo com Foster et al. (1981) o fator $K$, que diz respeito à erodibilidade do solo, tem por finalidade traduzir a suscetibilidade que o solo apresenta mediante os processos erosivos, e por este motivo, ele foi utilizado por Marques Neto; Viadana (2009) como indicador das características intrínsecas do solo quanto à fragilidade morfodinâmica.

Wischmeier; Smith (1978) propõem um nomograma para a determinação da erodibilidade, que pode ser expresso também pela equação 6 (RENARD et al., 1997).

$$
K=\frac{2,1 \cdot 10^{-4} \cdot(12-O M) \cdot M^{1,14}+3,25 \cdot(s-2)+2,5 \cdot(p-3)}{100 \cdot 7,59}
$$

Onde: $K=$ erodibilidade do solo (t.ha.h.ha-1. $\mathrm{MJ}^{-1} \cdot \mathrm{mm}^{-1}$ ); $O M=$ porcentagem de matéria orgânica no solo (\%); $M=$ parâmetro referente à textura dado por [(\% de silte) ( $\%$ de silte $+\%$ de areia)]; $s$ = código da classe de estrutura, 1 (granular muito fina), 2 (granular fina), 3 (granular média ou grande) e 4 (de blocos, laminar ou maciça); $p$ = código da classe de permeabilidade, 1 (rápida), 2 (moderada a rápida), 3 (moderada), 4 (lenta a moderada), 5 (lenta) e 6 (muito lenta).

Utilizou-se o levantamento de solos do estado de Santa Catarina (EMBRAPA, 2004) para obter a informação da textura dominante de cada solo que compõe a bacia hidrográfica. Em seguida, com o auxílio da pirâmide textural da Embrapa (2014), foi possível determinar as frações de areia, silte e argila para cada um dos solos presentes na bacia hidrográfica. Estas frações foram utilizadas na determinação de $M$. Como algumas unidades de mapeamento são compostas por mais de um tipo de solo, nestes casos utilizou-se a média de $M$ dos tipos de solo constituintes de determinada unidade de mapeamento para obter um só valor de $M$ para cada uma delas. 
A caracterização quanto à estrutura do solo foi obtida no boletim de solos desenvolvido pela Embrapa (2004). Essas informações foram interpretadas conforme a tabela 2 no intuito de se adotar um valor de $s$ para cada tipo de solo. $O$ valor final de $s$ de cada unidade de mapeamento foi calculado por meio de média aritmética.

Para determinar a classe de permeabilidade $p$ para cada unidade de mapeamento, estimou-se a condutividade hidráulica saturada para cada um dos tipos de solo existentes na bacia utilizando o software Rosetta Lite Version 1.1 que foi proposto por Schaap et al. (2001), sendo que, neste caso, os dados de entrada foram as porcentagens de areia, silte e argila já obtidas anteriormente. Em seguida verificou-se em qual classe de permeabilidade dentre as definidas pela USDA (U.S. Department of Agriculture) se encaixavam os valores de condutividade hidráulica saturada (USDA, 2010). Não foi necessário adotar média, pois em todos os casos em que unidades de mapeamento eram constituídas por mais de um tipo de solo, todos se enquadraram na classe de permeabilidade de lenta a moderada.

\section{Tabela 2 - Tipo de solo, estrutura de acordo com o boletim de solos desenvolvido pela Embrapa (2004), o intervalo cabível para a descrição e valores adotados}

\begin{tabular}{lccc}
\hline \multicolumn{1}{c}{ Solo } & Estrutura conforme o boletim de solos & $\begin{array}{c}\text { Intervalo } \\
\text { adotado }\end{array}$ & $\begin{array}{c}\text { Valor de } \boldsymbol{s} \\
\text { adotado }\end{array}$ \\
\hline Cambissolo Háplico & Fraca a moderada pequena e média & 2 e 3 & 2,5 \\
Neossolo Litólico & Moderada pequena muito pequena granular & 1 e 2 & 1,5 \\
Nitossolo Vermelho & Moderada pequena média granular & 2 e 3 & 2,5 \\
Latossolo Vermelho & Forte pequena e muito pequena granular & 1 e 2 & 1,5 \\
Latossolo Bruno & Fraca pequena média granular e em blocos & 2 e 3 & 2,5 \\
& subangulares & &
\end{tabular}

A porcentagem de matéria orgânica é um atributo que apresenta alta variabilidade espacial. No levantamento de solos não se dispõe de dados médios para esse atributo para cada tipo de solo. Apesar de alguns trabalhos terem determinado essa característica em laboratório, verificou-se que o solo está submetido a manejos muito específicos em cada situação (PEIXOTO et al., 2002; VERLENGIA; GARGANTINI, 1968). Diante do exposto, adotou-se $O M$ igual a $2 \%$ para todas as unidades de mapeamento por ser o valor intermediário no intervalo possível ( 0 a $4 \%$ ). Verificou-se que a sensibilidade do cálculo de $K$ ao parâmetro $O M$ pode chegar a no máximo $15 \%$, porém ao se adotar o mesmo valor para todas as unidades de mapeamento minimizou-se uma possível falsa interferência no cálculo final de perda de solo.

Assim, para gerar o resultado deste fator, utilizou-se o mesmo mapa fornecido pela Embrapa e apenas adicionou-se uma nova coluna na tabela de atributos com o valor de $K$ correspondente a cada unidade de mapeamento.

\section{Fator $L S$}

O fator $L S$, conhecido como fator topográfico, traduz a influência do relevo sobre os processos erosivos e de sedimentação. Para a determinação deste fator são necessários dados, que forneçam altitude mínima, média e máxima, a declividade do terreno, e também o comprimento da vertente (PINET; SOURIAU, 1988; SUMMERFIELD; HULTON, 1994).

O fator $L$ consiste na distância existente entre o local de origem do fluxo superficial - ponto de maior altitude - até o local de menor declive, locais estes onde ocorre 
a deposição de sedimentos. De acordo com Mitasova et al. (1995), quanto maior $L$, maior a perda de solo, já que quanto maior a distância entre o ponto de maior e menor altitude, maior o arraste de água sobre o solo, e maior a quantia de sedimentos gerada.

O fator de inclinação da encosta $S$ é um parâmetro que também considera, de forma indireta, o efeito do deflúvio superficial do solo (RIGHETTO, 1998). Sendo o ângulo de inclinação da encosta $\theta$, a declividade do terreno igual a $\operatorname{sen}(\theta)$ é considerada na USLE por meio de uma equação empírica, que é denominada fator de inclinação da encosta S (WISCHMEIER; SMITH 1978). $L S:$

Wischmeier; Smith (1978) propõem a equação 7 para a determinação do fator

$$
L S=\left(\frac{x}{22,1}\right)^{m} \cdot\left(65,41 \cdot s^{2}+4,59 \cdot s+0,065\right)
$$

Onde: $x=$ comprimento da encosta $(m) ; m=$ expoente função da declividade predominante (igual a 0,5 quando a declividade é maior ou igual a $5 \% ; 0,4$ quando a declividade está entre 3,5 e 4,5\%; 0.3 quando a declividade está entre 1,0 e 3,0\%; e 0.2 para declividade predominantemente menor que $1 \%) ; s=$ declividade do terreno (adimensional).

Tombuş et al. (2012) afirmam que é possível obter um valor aproximado de $x$ aplicando a equação 8 .

$$
x=\text { flow accumulation tamanho do pixel }
$$

Onde: $x=$ comprimento da encosta $(\mathrm{m})$; sendo flow accumulation adimensional, obtido por meio de ferramentas de geoprocessamento, e o tamanho do pixel informação referente à resolução do arquivo matricial utilizado $(\mathrm{m})$.

O "flow accumulation" foi obtido a partir do processamento do Modelo Digital de Elevação (MDE) da bacia hidrográfica do Lajeado São José, que foi obtido no site da Empresa de Pesquisa Agropecuária e Extensão Rural de Santa Catarina (Epagri/Ciram) na resolução de $30 \mathrm{~m}$, de forma gratuita. Primeiramente utilizou-se a ferramenta "fill", que é utilizada para remover possíveis depressões do raster. Posteriormente, com o auxílio da ferramenta "flow direction", determinou-se a direção de fluxo de forma automática, atribuindo valores específicos para cada direção de fluxo na grade de dados. Depois, com o auxílio da "flow accumulation", foi calculada a quantidade de células que drenam para determinada célula de análise.

Para a determinação da declividade (s), utilizando-se do MDE, prosseguiu-se com a utilização da ferramenta "slope", que gera um mapa de declividades da bacia hidrográfica em graus. Depois, com o auxílio da "Raster calculator" calculou-se o seno do "slope".

Tendo-se o mapa do "flow accumulation" e o mapa do sen(slope), a equação 9 utilizada para calcular o fator $L S$.

$$
L S=\left(\frac{\text { flow accumulation } \cdot \text { tamanho do pixel }}{22,1}\right)^{m} \cdot\left(65,41 \cdot[\operatorname{sen}(\operatorname{slope})]^{2}+4,59 \cdot[\operatorname{sen}(\operatorname{slope})]+0,065\right)
$$




\section{Fator $C P$}

O fator de cobertura, uso e manejo do solo, $C$, é definido pela relação de perda de solo entre o solo alterado por práticas de cultura e o solo exposto, de acordo com Righetto (1998) e Renard et al. (1997).

Os 2 métodos mais aplicados para estimativa do fator $C$ são: (1) por meio de valores empíricos disponíveis na literatura para cada classe de uso do solo; (2) a partir do NDVI (Normalized Difference Vegetation Index).

De acordo com Tucker (1979) o NDVI pode ser determinado pela equação 10.

$$
N D V I=\frac{\rho_{N I R}-\rho_{R e d}}{\rho_{N I R}+\rho_{R e d}}
$$

Onde: $N D V I=$ assume valores de -1 a +1 com valores mais altos atribuídos a áreas com maior cobertura vegetal; $\rho_{\text {NIR }}=$ reflectância espectral de superfície na faixa do infravermelho; $\rho_{\text {Red }}=$ superfície de reflectância espectral na banda do vermelho.

O NDVI foi calculado por meio do software ArcGis 10.3.1, a partir das bandas 4 e 5, sendo estas correspondentes a banda do infravermelho e vermelho, respectivamente, das imagens do satélite LANDSAT 8, sensor OLI, disponíveis gratuitamente no site do INPE (Instituto Nacional de Pesquisas Espaciais). Foi selecionada uma imagem com melhor visibilidade capturada a cada 2 meses no ano de 2015, resultando em um total de 6 imagens com datas específicas em: 20/03/2015; 07/05/2015; 26/07/2015; 28/09/2015; 14/10/2015; e 17/12/2015. O intuito de se adotar esse intervalo temporal foi calcular um NDVI mensal médio representativo para a bacia.

A equação 10 foi aplicada para cada uma das imagens de satélite por meio de álgebra de mapas gerando um NDVI para cada uma delas. Posteriormente, com a mesma ferramenta, encontrou-se uma média dos 6 mapas de NDVI.

O cálculo de $C$ foi realizado por meio da aplicação da equação 11 proposta por van der Knijff, Jones e Montanarella (2001), com a mesma ferramenta.

$$
C=\frac{-N D V I+1}{2}
$$

Um mapa atual do fator $C$ foi gerado também por meio da atribuição de valores (Tabela 3) para cada uso do solo observado em um mapa de uso do solo. O mapa de uso do solo foi elaborado no software Spring 5.3, por meio da classificação automática supervisionada da imagem do satélite LANDSAT 8, sensor OLI, obtida gratuitamente no site do INPE. A data de captura da imagem utilizada foi 07 de abril de 2016.

Na tabela de atributos do mapa de uso do solo acrescentou-se uma coluna correspondente aos valores de $C$ (Tabela 3 ). Posteriormente, convertendo o formato do arquivo para raster, selecionou-se o atributo $C$ para compor o arquivo gerado.

\section{Tabela 3 - Classes de uso do solo e valor de $C$ adotado para cada uma}

\begin{tabular}{ccc}
\hline $\begin{array}{c}\text { Classe de uso } \\
\text { do solo }\end{array}$ & Valor de $\boldsymbol{C}$ & Referência \\
\hline Agricultura & 0,290 & BERTONI; LOMBARDI NETO (1985) \\
Vegetação & 0,010 & BERTONI; LOMBARDI NETO (1985) \\
Mancha urbana & 0,200 & MORGAN (1995) \\
Solo exposto & 0,404 & BERTONI; LOMBARDI NETO (1985) \\
Cursos d'água & 0,000 & BERTONI; LOMBARDI NETO (1985) \\
\hline
\end{tabular}


O fator $P$ corresponde a valores para práticas contra erosão em função do manejo do solo, de acordo com Righetto (1998). Com o objetivo de estimar a perda de solo potencial da bacia, atribuiu-se valor 1 ao fator $P$, considerando que não existe a adoção de práticas conservacionistas na área da bacia hidrográfica do Lajeado São José, que seria a situação mais pessimista possível.

\section{Estimativa da produção de sedimentos para 30 anos}

Debastiani (2015) avaliou as alterações no uso do solo no perímetro urbano da bacia do Lajeado São José para o intervalo de 1986 a 2014. Com base nos dados do trabalho mencionado, estimou-se uma tendência de aumento anual da área urbana de $1,8 \%$.

Posteriormente, gerou-se o polígono da área urbana estimado para 2046 tendo como base o mapa de uso do solo gerado para 2016 com o auxílio da ferramenta "Buffer" no ArcGis 10.3.1,. Visando a redução de possíveis erros mediante a sobreposição do "Buffer", utilizou-se da ferramenta "Dissolve", que promoveu uma agregação em todo o polígono transformando-o em um só.

Depois, com o auxílio da "Erase" realizou-se a subtração entre o mapa de uso do solo atual e o "Buffer" desenvolvido para a mancha urbana futura, obtendo-se como resultado um mapa que compunha todas as classes de uso do solo da bacia, exceto a mancha urbana.

Considerando que, em 30 anos a única classe a ter aumento de área seria a correspondente à mancha urbana, por meio da ferramenta "Union" procedeu-se com a união do "Buffer" e do mapa obtido por meio da "Erase", obtendo-se o mapa de uso do solo para 2046.

Na tabela de atributos do mapa de uso do solo projetado para 30 anos acrescentou-se uma coluna correspondente aos valores de $C$ (Tabela 3). Posteriormente, convertendo o formato do arquivo para raster, selecionou-se o atributo $C$ para compor o arquivo gerado.

Os demais fatores $R, K$, e $L S$ permaneceram inalterados para o cálculo da estimativa da produção de sedimentos da bacia hidrográfica do Lajeado São José em 2046.

\section{RESULTADOS E DISCUSSÃO}

\section{Fator $R$}

O maior valor de $R$ médio mensal foi obtido na estação de Seara, chegando a $595,416 \mathrm{MJ} \cdot \mathrm{mm} \cdot \mathrm{ha}^{-1} \cdot \mathrm{h}^{-1}$, enquanto o menor é da estação de Quilombo, chegando a $370,488 \mathrm{MJ} \cdot \mathrm{mm} \cdot \mathrm{ha}^{-1} \cdot \mathrm{h}^{-1}$. A estação do Vila Real apresentou um $R$ de 589,002 MJ.mm.ha${ }^{1} \cdot \mathrm{h}^{-1}$, a da Prefeitura 486,046 MJ.mm.ha-1.h-1 e a da UFFS 450,831 MJ.mm.ha-1.h-1.

A variabilidade espacial e temporal da precipitação, em especial das chuvas erosivas na bacia, é evidente. Pode-se observar que apesar de os maiores valores de $R$ não ocorrerem nos mesmos meses em todas as estações pluviométricas se concentram na primavera e no verão, período no qual as chuvas intensas são características e mais frequentes na região. Na estação da UFFS o maior $R$ foi obtido no mês de novembro, nas estações de Seara e da Prefeitura no mês de março, na estação de Vila Real em fevereiro e na estação de Quilombo em outubro (Figura 3). 


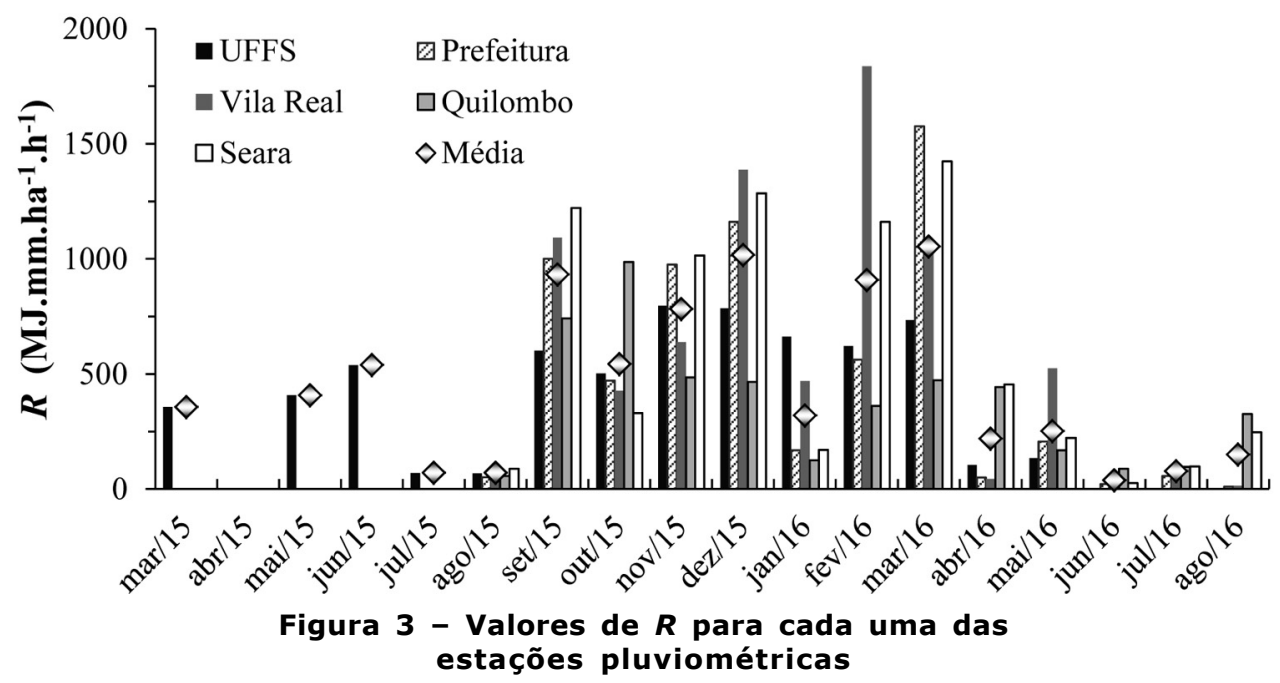

Nenhum mês da série de dados apresentou precipitação zero, apesar de, para algumas estações, a erosividade ser nula, já que o início do monitoramento ocorreu mais tarde.

A figura $4 a$ apresenta o resultado para o fator $R$ na bacia hidrográfica do Lajeado São José. De acordo com o mapa, o valor médio mensal do fator para a área da bacia hidrográfica é de 533,023 MJ.mm.ha-1.h-1.

Os maiores valores de $R$ ocorrem na porção leste da bacia hidrográfica, área esta composta, em sua maior parte, pela unidade de mapeamento de solos composta por Nitossolo Vermelho e Cambissolo Háplico, coincidindo ainda com a porção mais urbanizada da bacia hidrográfica.

Observou-se uma redução da erosividade na porção sul da bacia hidrográfica, esta pode estar possivelmente relacionada com a altimetria da bacia, já que justamente neste local tem-se os menores valores de altitude.

Schick et al. (2014) determinaram o $R$ médio mensal igual a 419,42 MJ.mm.ha${ }^{1} . \mathrm{h}^{-1}$ para Lages-SC utilizando dados entre os anos de 1989 e 2012. Em Urussanga, também em Santa Catarina, a erosividade média mensal foi estimada em 614,63 MJ.mm.ha-1.h $\mathrm{h}^{-1}$ (VALVASSORI; BACK, 2014). Waltrick et al. (2015) determinaram o fator $R$ médio mensal de $750,00 \mathrm{MJ} \cdot \mathrm{mm} \cdot \mathrm{ha}^{-1} \cdot \mathrm{h}^{-1}$ para 114 locais do estado do Paraná. Galdino et al. (2015) estimaram a erosividade média anual das chuvas na bacia do Alto Paraguai em território brasileiro de $6800 \mathrm{MJ} \cdot \mathrm{mm} \cdot \mathrm{ha}^{-1} \cdot \mathrm{h}^{-1}$. Gómez (2012), ao calcular o valor de erosividade a partir de 2156 estações pluviométricas distribuídas no território brasileiro, encontrou um $R$ médio mensal de $1250,00 \mathrm{MJ} \cdot \mathrm{mm} \cdot \mathrm{ha}^{-1} \cdot \mathrm{h}^{-1}$, variando este entre 166,67 e 2333,33 MJ.mm.ha-1.h-1.

Os resultados encontrados para o fator $R$ são bastante coerentes, já que no estado de Santa Catarina, Paraná e até mesmo no Brasil, os valores para este fator apresentam-se bastante próximos. 


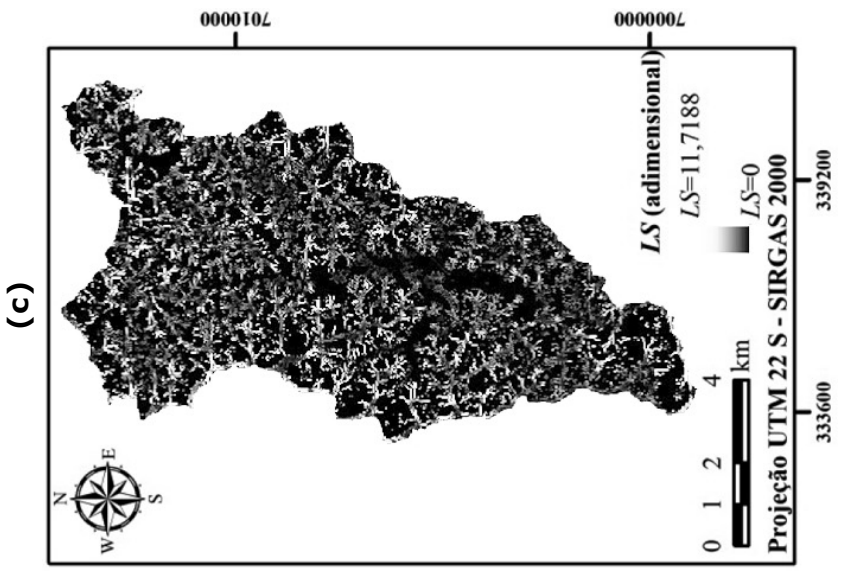

눈

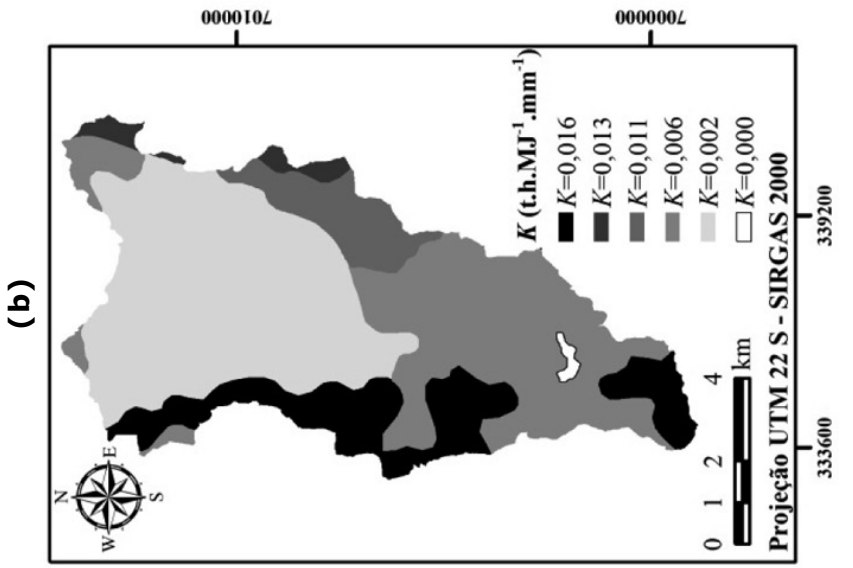

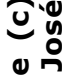

ơ

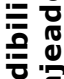

ำ

(1) 웅

อ

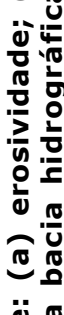

$\ddot{0}$ ס

ก ㅇำ

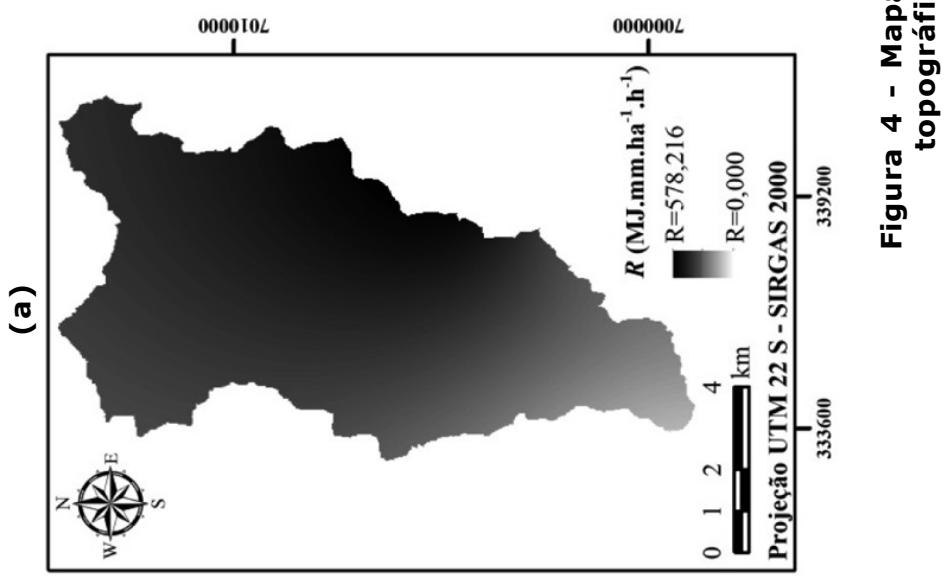




\section{Fator $K$}

O mapa de classificação de solos utilizado no processo de determinação do fator $K$ apresenta oito unidades de mapeamento inseridas na bacia de estudo, sendo que 2 das unidades são compostas por 3 diferentes tipos de solos, outras 2 das unidades por 2 diferentes tipos de solo, e 4 das unidades restantes por somente um tipo de solo (Tabela 4).

A diferença existente entre o somatório das áreas de cada unidade de mapeamento e a área total da bacia hidrográfica se dá em virtude da existência de áreas urbanizadas e corpos d'água, sendo estas correspondentes a 0,035 ha e 33,599 ha, respectivamente.

Os tipos de solo predominantes na bacia hidrográfica são Nitossolo Vermelho e Latossolo Bruno. E as unidades de mapeamento com maior área são as unidades 5 e 6, com $K$ igual a 0,002 t.h.MJ ${ }^{-1} \cdot \mathrm{mm}^{-1}$ e 0,007 t.ha.h.ha-1. $\mathrm{MJ}^{-1} \cdot \mathrm{mm}^{-1}$, respectivamente. A erodibilidade média dos solos é igual a 0,009 t.h.MJ-1. $\mathrm{mm}^{-1}$ (Figura $4 \mathrm{~b}$ ).

\section{Tabela 4 - Unidades de mapeamento com seus tipos de solo, textura, respectivas espessuras, valores de $M$, classe de estrutura ( $s$ ), condutividade hidráulica saturada $(K s)$, e fator $K$}

\begin{tabular}{|c|c|c|c|c|c|c|c|c|}
\hline $\begin{array}{c}\text { Unidade de } \\
\text { mapeamento }\end{array}$ & 1 & 2 & 3 & 4 & 5 & 6 & 7 & 8 \\
\hline Área (ha) & 991,573 & 166,540 & 212,293 & 40,492 & 3167,610 & 2204,430 & 549,121 & 266,692 \\
\hline Tipo de solo 1 & $\begin{array}{l}\text { Cambissolo } \\
\text { Háplico }\end{array}$ & $\begin{array}{l}\text { Cambissolo } \\
\text { Háplico }\end{array}$ & $\begin{array}{l}\text { Nitossolo } \\
\text { Vermelho }\end{array}$ & $\begin{array}{l}\text { Nitossolo } \\
\text { Vermelho }\end{array}$ & $\begin{array}{l}\text { Nitossolo } \\
\text { Vermelho }\end{array}$ & $\begin{array}{l}\text { Latossolo } \\
\text { Bruno }\end{array}$ & $\begin{array}{l}\text { Nitossolo } \\
\text { Vermelho }\end{array}$ & $\begin{array}{l}\text { Cambissolo } \\
\text { Háplico }\end{array}$ \\
\hline Textura & Argilosa & Argilosa & $\begin{array}{l}\text { Muito } \\
\text { argilosa }\end{array}$ & $\begin{array}{l}\text { Muito } \\
\text { argilosa }\end{array}$ & $\begin{array}{l}\text { Muito } \\
\text { argilosa }\end{array}$ & $\begin{array}{l}\text { Muito } \\
\text { argilosa }\end{array}$ & $\begin{array}{l}\text { Muito } \\
\text { argilosa }\end{array}$ & Argilosa \\
\hline$\%$ areia & 26,25 & 26,25 & 10,00 & 10,00 & 10,00 & 10,00 & 10,00 & 26,25 \\
\hline \multirow{2}{*}{$\begin{array}{c}\text { \% argila } \\
\text { espessura } \\
(\mathrm{cm})\end{array}$} & $\begin{array}{l}26,25 \\
47,50\end{array}$ & $\begin{array}{l}26,25 \\
47,50\end{array}$ & $\begin{array}{l}10,00 \\
80,00\end{array}$ & $\begin{array}{l}10,00 \\
80,00\end{array}$ & $\begin{array}{l}10,00 \\
80,00\end{array}$ & $\begin{array}{l}10,00 \\
80,00\end{array}$ & $\begin{array}{l}10,00 \\
80,00\end{array}$ & $\begin{array}{l}26,25 \\
47,50\end{array}$ \\
\hline & $60-150$ & $60-150$ & $>150$ & $>150$ & $>150$ & $>150$ & $>150$ & $60-150$ \\
\hline Tipo de solo 2 & $\begin{array}{l}\text { Neossolo } \\
\text { Litólico }\end{array}$ & $\begin{array}{l}\text { Neossolo } \\
\text { Litólico }\end{array}$ & - & - & - & - & $\begin{array}{l}\text { Cambissolo } \\
\text { Háplico }\end{array}$ & $\begin{array}{l}\text { Neossolo } \\
\text { Litólico }\end{array}$ \\
\hline \multirow{5}{*}{$\begin{array}{c}\text { Textura } \\
\% \text { areia } \\
\% \text { silte } \\
\text { \% argila } \\
\text { espessura } \\
\text { (cm) } \\
\end{array}$} & \multirow{4}{*}{$\begin{array}{l}\text { Média } \\
45,00 \\
37,50 \\
17,50\end{array}$} & Argilosa & - & - & - & - & Argilosa & Média \\
\hline & & & - & - & - & - & 26,25 & 45,00 \\
\hline & & 26,25 & - & - & - & - & 26,25 & 37,50 \\
\hline & & 47,50 & - & - & - & - & 47,50 & 17,50 \\
\hline & $<60$ & $<60$ & - & - & - & - & $60-150$ & $<60$ \\
\hline Tipo de solo 3 & $\begin{array}{l}\text { Nitossolo } \\
\text { Vermelho }\end{array}$ & - & - & - & - & 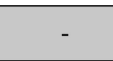 & - & $\begin{array}{l}\text { Nitossolo } \\
\text { Vermelho }\end{array}$ \\
\hline Textura & \begin{tabular}{|l} 
Muito \\
argilosa
\end{tabular} & - & - & - & - & - & - & $\begin{array}{l}\text { Muito } \\
\text { argilosa }\end{array}$ \\
\hline$\%$ areia & 10,00 & - & - & - & - & - & - & 10,00 \\
\hline$\%$ silte & 10,00 & - & - & - & - & - & - & 10,00 \\
\hline$\%$ argila & 80,00 & - & - & - & - & - & - & 80,00 \\
\hline $\begin{array}{c}\text { espessura } \\
(\mathrm{cm})\end{array}$ & $>150$ & - & - & - & - & - & - & $>150$ \\
\hline$M$ & 1557,29 & 1378,13 & 200 & 200 & 200 & 200 & 789,063 & 1557,29 \\
\hline$s$ & 2,167 & 2 & 2,5 & 2,5 & 1,5 & 2,5 & 2,5 & 2,167 \\
\hline$K s\left(\right.$ in. $\left.h^{-1}\right)$ & 0,2 & 0,2 & 0,3 & 0,3 & 0,3 & 0,3 & 0,2 & 0,2 \\
\hline $\begin{array}{c}K \\
\left(\mathrm{t} . \mathrm{h} . \mathrm{MJ}^{-1} \cdot \mathrm{mm}^{-1}\right) \\
\end{array}$ & 0,016 & 0,013 & 0,006 & 0,006 & 0,002 & 0,006 & 0,01 & 0,016 \\
\hline
\end{tabular}

As unidades de mapeamento 1 e 8 , apresentam os maiores valores de erodibilidade - 0,016 t.ha.h.ha-1. MJ-1. $\mathrm{mm}^{-1}$ e recobrem $16,5 \%$ da superfície da bacia 
hidrográfica. Esse resultado está relacionado ao fato de ambas serem compostas por 3 tipos de solo (Cambissolo Háplico, Neossolo Litólico e Nitossolo Vermelho) com características de textura mais grossa e menos estruturada.

Os maiores valores de erodibilidade são observados justamente nas porções onde o fator topográfico também o é, o que configura maior suscetibilidade do solo com relação a relevos mais acidentados.

Risso et al. (2004) encontraram valores de erodibilidade entre 0,001 t.ha.h.ha${ }^{1} \cdot \mathrm{MJ}^{-1} \cdot \mathrm{mm}^{-1}$ e 0,005 t.ha.h.ha-1. $\mathrm{MJ}^{-1} \cdot \mathrm{mm}^{-1}$ para a bacia hidrográfica do Alto Taquari, localizada no Mato Grosso do Sul.

Gómez (2012) encontrou valores de $K$ para todo o território brasileiro, obtendo valores médios entre 0,0060 t.ha.h.ha-1.MJ-1. $\mathrm{mm}^{-1}$ e 0,00439 t.ha.h.ha-1. MJ $\mathrm{MJ}^{-1} \cdot \mathrm{mm}^{-1}$. Portanto, a ordem de grandeza da erodibilidade na bacia apresenta-se coerente com outras determinações.

\section{Fator $L S$}

Os valores do fator topográfico na bacia hidrográfica do Lajeado São José variam entre 0 e 11,719, sendo que o valor médio para a área é de 0,236 (Figura 4c). Mediante os valores de $L S$ obtidos, observou-se a predominância de valor zero. Este fato contribui na redução de taxas de escoamento superficial, fazendo com que a erosão laminar seja desfavorecida. Nestes casos o relevo não é promotor da aceleração, mas sim amenizador dos processos erosivos.

As vertentes consideradas mais declivosas estão localizadas de forma predominante na porção oeste da bacia hidrográfica, região com maior altimetria. Neste caso a participação do relevo influencia no aumento da aceleração da perda de solo em função do aumento de $L S$.

Risso et al. (2004) encontraram valores do fator LS para a bacia hidrográfica do Alto Taquari, de relevo bastante íngreme, entre 0,01 e 166,00. Silva (2008) determinou o fator topográfico em vertentes pouco declivosas no município de Sorocaba, e encontrou uma variação do fator entre 0 e 100.Como a bacia do Lajeado São José apresenta relevo montanhoso e suave-ondulado, o intervalo de valores de $L S$ encontrados neste trabalho apresenta-se coerente.

\section{Fator $C P$}

Atualmente, o principal uso da bacia hidrográfica do Lajeado São José é agrícola, ocupando cerca de $43,87 \%$ da área da bacia (Figura $5 a$ e Tabela 5). O fator CP obtido a partir da aplicação de valores tabelados indicados na literatura para cada uso do solo apresenta o valor médio de 0,506 para toda a bacia.

No fator $C P$, os valores estimados a partir do índice de NDVI variaram entre $0 \mathrm{e}$ 0,586 , sendo o valor médio do fator para toda a área da bacia hidrográfica de 0,352 (Figura 5b).

Mediante análise espacial, foi possível observar que os maiores valores de $C$ foram obtidos justamente nas porções de área compostas por urbanização. Essa é uma das principais diferenças entre os 2 métodos aplicados para obtenção do fator $C$, pois quando são utilizados valores tabelados, os usos de solo exposto e a agricultura é que apresentam os maiores valores de $C$ (Figura $5 c$ ). 
(a)

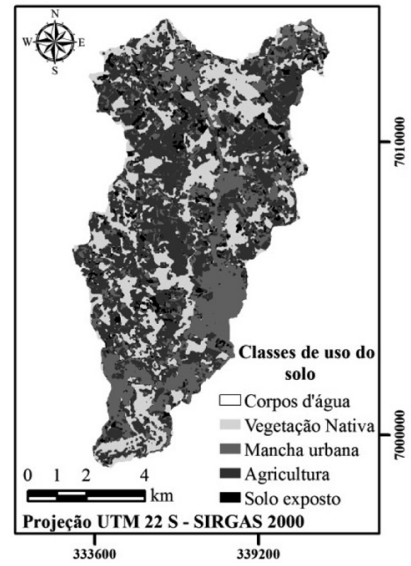

(b)

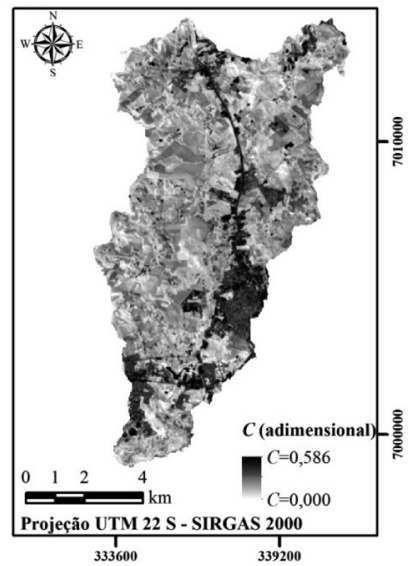

(c)

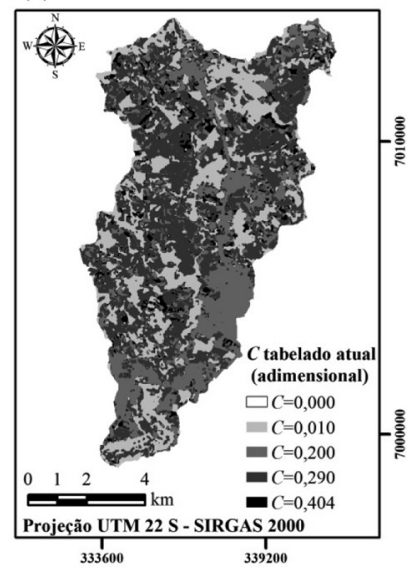

Figura 5 - Mapas de: (a) uso do solo atual; (b) fator $C$ atual (2016) calculado a partir do NDVI; e (c) de valores tabelados na literatura

Tabela 5 - Classes de uso do solo, área de ocupação em hectares e em porcentagem com relação à área total da bacia hidrográfica para o ano de 2016 e projeção para 2046

\begin{tabular}{crrrr}
\hline Classe de uso & \multicolumn{2}{c}{ Área atual (2016) } & \multicolumn{2}{c}{ Área em 2046 } \\
\cline { 2 - 5 } do solo & (ha) & $\mathbf{( \% )}$ & (ha) & (\%) \\
\hline Agricultura & 3348,659 & 43,87 & 2356,008 & 30,87 \\
Vegetação & 1955,337 & 25,62 & 1754,574 & 22,99 \\
Mancha urbana & 1945,703 & 25,49 & 3352,350 & 43,92 \\
Solo exposto & 380,630 & 4,99 & 169,016 & 2,21 \\
Cursos d'água & 2,116 & 0,03 & 0,469 & 0,01 \\
\hline
\end{tabular}

De acordo com Righetto (1998), para solo exposto, que não possui qualquer tipo de proteção contra a erosão, o valor de $C$ deve ser 1 , em contrapartida, para solo que possui vegetação nativa densa, o valor de $C$ deve ser 0,01 . Grande parte da área da bacia hidrográfica é ocupada por atividades de agricultura e de urbanização, obtendo ainda fragmentos de vegetação nativa, por este motivo, pode-se afirmar que existe, de certa forma, proteção contra erosão, e em virtude disso o valor de $C$ não chega a 1 na bacia hidrográfica do Lajeado São José.

\section{Estimativa de perda de solo}

Na estimativa utilizando o $C$ obtido a partir do NDVI o potencial de produção de sedimentos da bacia hidrográfica variou entre 0 e 30,166 t.ha-1. mês $^{-1}$, sendo que a taxa média é de $3,88{\mathrm{t} . \mathrm{ha}^{-1} \text {. ano }}^{-1}$ (Figura 6a), enquanto na estimativa utilizando os valores de $C$ tabelados, o potencial de produção variou entre 0 e 26,652 t.ha-1. mês $^{-1}$, sendo a taxa média de produção de sedimentos igual a 2,41 t.ha-1.ano-1 (Figura 6b). Sendo assim, a estimativa com valores de $C$ tabelados é aproximadamente $38 \%$ menor do que aquela obtida a partir do NDVI. Apesar de o cálculo a partir do NDVI resultar em uma estimativa mais pessimista, tem uma possível fragilidade, que é a previsão de maiores taxas de produção de sedimento na área urbana. 


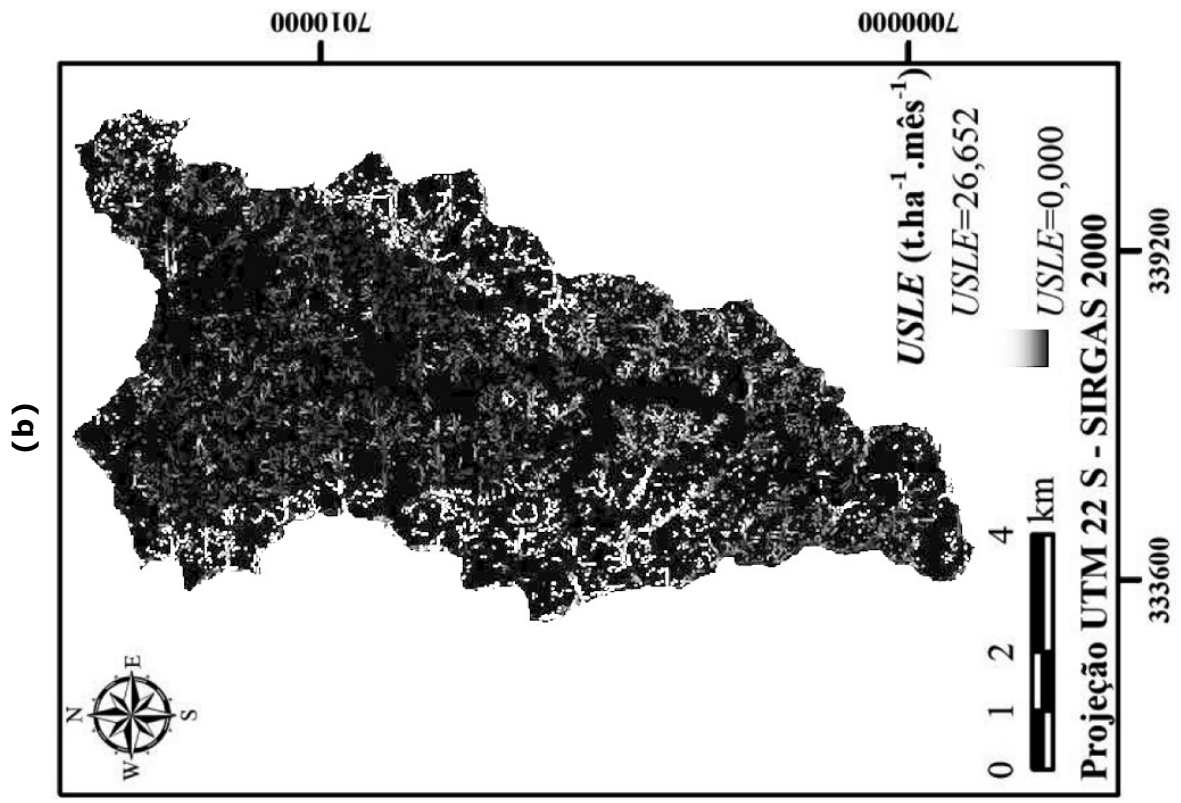

ญू

인

亿

용 꾼

苗

空

ב

으

ช

은

는

인

닌

正

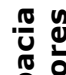

응

\%

을

吾

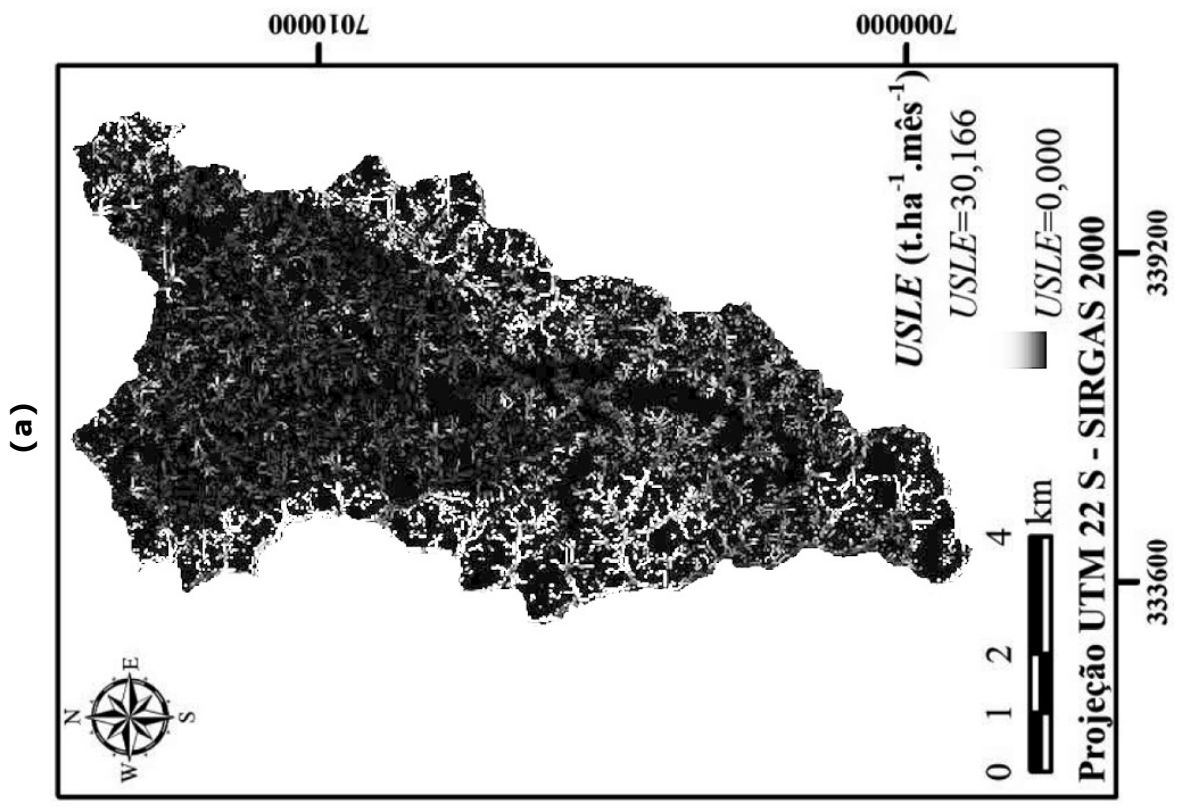

용

और

$\stackrel{0}{8} \stackrel{0}{\circ}$

울눈

닌

중

인 0

응

ง ํํํ

줄

농

(5)

잉

(1)

ชั

n

응 음

$\sum$

1.

0

존 
Vale destacar que a USLE possui capacidade de estimar a perda de solo causada por erosões do tipo laminar, e não leva em conta o processo de deposição, de acordo com Wischmeier; Smith (1978). Logo, os valores obtidos neste trabalho referem-se à produção de sedimentos sem considerar a ocorrência do fenômeno de deposição de sedimentos.

As maiores taxas de perda de solo foram observadas nas áreas mais próximas ao divisor de águas, consequentemente, as áreas com maior altimetria e encostas mais declivosas. Diante do exposto, pode-se afirmar que apesar de a USLE estimar apenas a erosão, todos os resultados obtidos estão coerentes com a teoria do ciclo hidrossedimentológico, que prevê que áreas de cabeceira são aquelas onde ocorre a maior parte da erosão na bacia hidrográfica. Além disso, observando-se espacialmente, as áreas com maiores taxas de perda de solo coincidem com as áreas que apresentam maiores valores de $K$ e de $L S$, o que implica em dizer que, quanto maiores os valores de erodibilidade e fator topográfico, maior a perda de solo.

Verificando a tabela 6 , pode-se constatar que a taxa de produção de sedimentos pode variar bastante, sendo esta dependente do uso principal do solo, e também do tamanho da área de estudo. Para tanto, considerando que a maior parte do solo da bacia hidrográfica do Lajeado São José é utilizado para fins de agricultura, constatase que os valores encontrados neste trabalho apresentam ordem de grandeza compatível. Além disso, em um estudo sobre a influência do uso do solo na produção de sedimentos na escala de parcela, Thomaz (2007) encontrou taxa de 2,77 t.ha- ${ }^{-1}$. no $^{-1}$ na parcela caracterizada por agricultura.

\section{Tabela 6 - Taxas de perda de solo estimadas em áreas de estudo no território brasileiro}

\begin{tabular}{|c|c|c|c|c|c|}
\hline LOCAL & UF & ÁREA (ha) & $\begin{array}{l}\text { USO DE SOLO } \\
\text { PREDOMINANTE }\end{array}$ & $\begin{array}{c}\text { TAXA DE PERDA DE } \\
\text { SOLO } \\
\left(\mathrm{t} . \mathrm{ha}^{-1} \cdot \mathrm{ano}^{-1}\right)\end{array}$ & REFERÊNCIA \\
\hline $\begin{array}{l}\text { Município de Paraíso } \\
\text { das Águas }\end{array}$ & MS & 503500 & $\begin{array}{c}\text { Campo sujo, pastagem } \\
\text { e agricultura }\end{array}$ & 0 a 1307,32 & Barbosa et al. (2015) \\
\hline Fazenda Canchin & SP & 1500 & Pastagem & 0,39 a 42 & Silva et al. (2010) \\
\hline $\begin{array}{l}\text { Bacia hidrográfica do } \\
\text { Alto Taquari }\end{array}$ & MS & 2845060 & Agricultura & 0 a 200 & Risso et al. (2004) \\
\hline $\begin{array}{l}\text { Bacia hidrográfica do } \\
\text { Ribeirão Maringá }\end{array}$ & PR & 9037 & Agricultura & 0 a 20 & $\begin{array}{c}\text { Santos e Morais } \\
(2012)\end{array}$ \\
\hline $\begin{array}{l}\text { Bacia hidrográfica do } \\
\text { Córrego Arapuca }\end{array}$ & PR & 169 & Agricultura & 0 a 30 & $\begin{array}{l}\text { Petsch e Monteiro } \\
\text { (2011) }\end{array}$ \\
\hline $\begin{array}{l}\text { Sub-bacia } \\
\text { hidrográfica do Rio } \\
\text { Coruja/Bonito }\end{array}$ & SC & 5256 & Agricultura & 0 a 16 & Vieira (2008) \\
\hline $\begin{array}{l}\text { Microbacia do } \\
\text { Ceveiro }\end{array}$ & SP & 1990 & $\begin{array}{l}\text { Cultura de cana- } \\
\text { de-açúcar }\end{array}$ & $\begin{array}{l}4,5 \cdot 10^{-9} \mathrm{a} \\
107,2 \cdot 10^{-9}\end{array}$ & $\begin{array}{l}\text { Weill e Sparovek } \\
(2008)\end{array}$ \\
\hline $\begin{array}{l}\text { Bacia hidrográfica do } \\
\text { Mogi-Guaçú }\end{array}$ & SP & 1136094 & $\begin{array}{l}\text { Cultura de cana- } \\
\text { de-açúcar }\end{array}$ & $\begin{array}{c}0 \mathrm{a} \\
1,487.10^{-6}\end{array}$ & $\begin{array}{c}\text { Weill, Rocha e } \\
\text { Lamparelli (2001) }\end{array}$ \\
\hline $\begin{array}{l}\text { Bacia hidrográfica do } \\
\text { Rio São José }\end{array}$ & CE & 4100 & Vegetação rasteira & 0 a 200 & Costa et al. (2013) \\
\hline $\begin{array}{l}\text { Município de } \\
\text { Sorocaba }\end{array}$ & SP & 44900 & Urbanização & 400 a 1600 & Silva (2008) \\
\hline
\end{tabular}

Bassi (1990) estimou a produção de sedimentos na bacia hidrográfica do Lajeado São José a partir de correlações entre a turbidez e a concentração de sedimentos em suspensão, e também de dados de turbidez e vazão diários entre abril de 1988 e outubro de 1989, totalizando a estimativa de produção para o período como 28000 toneladas de sedimento. Isto, corresponde a uma taxa de produção de sedimentos de 2,46 t. ha-1.ano-1. O método usado por Bassi (1990) determina a produção de sedi- 
mentos, ou seja, a quantidade de sedimentos que chegam ao exutório da bacia hidrográfica, diferente do método utilizado neste trabalho, que estima a erosão, ou seja, a quantidade de partículas de solo desprendidas/geradas em toda a área da bacia hidrográfica, e não somente o que deixa a bacia através do exutório. Esta pode ser a principal justificativa pela diferença existente entre o valor encontrado por Bassi (1990), e o valor encontrado neste trabalho a partir da utilização dos valores de $C$ definidos pelo NDVI. Contudo, o fato de floresta nativa ter sido substituída por outros usos também pode ter contribuído no aumento desta taxa.

\section{Estimativa da produção de sedimentos para 30 anos}

Verificando-se a figura 7 a e a tabela 5 , pode-se constatar que seguindo a tendência estatística das estimativas de Debastiani (2015), a área urbana terá um aumento de $18,43 \%$ em 30 anos substituindo áreas atualmente destinadas à agricultura. A comparação das figuras $5 c$ e $7 b$ evidencia a redução das áreas com fator $C$ igual a 0,29 e 0,404, sendo que em 2046 o valor médio de $C$ para a bacia seria de 0,353.

Mediante os resultados, a produção de sedimentos na bacia hidrográfica em 30 anos irá variar entre 0 e 26,652 t.ha-1. mês $^{-1}$, sendo que a taxa de perda de solo média chegará a 2,26 t.ha-1.ano-1 (Figura 7c).

Comparando este resultado com a produção atual de sedimentos na bacia hidrográfica (Figura $6 \mathrm{~b}$ ), pode-se observar a redução de $6,2 \%$. Isto se deve ao fato de que a bacia hidrográfica do Lajeado São José tem como principal uso do solo a agricultura, que de acordo com a projeção realizada, terá uma redução de aproximadamente $13 \%$ em sua área.

Contudo, a redução da taxa de produção de sedimentos não pode ser vista como positiva para o desenvolvimento da bacia hidrográfica. Com o aumento da área urbana a qualidade da água do Lajeado São José sofrerá modificações, já que os sedimentos podem atuar como portadores de uma série de poluentes que existem nestas áreas (CARVALHO, 2008). A elevada concentração de poluentes agregados aos sedimentos pode ser prejudicial, principalmente, porque eles podem ser portadores de elementos como metais pesados, hidrocarbonetos, agrotóxicos e patógenos, concordam Collischonn; Tucci (1998). 


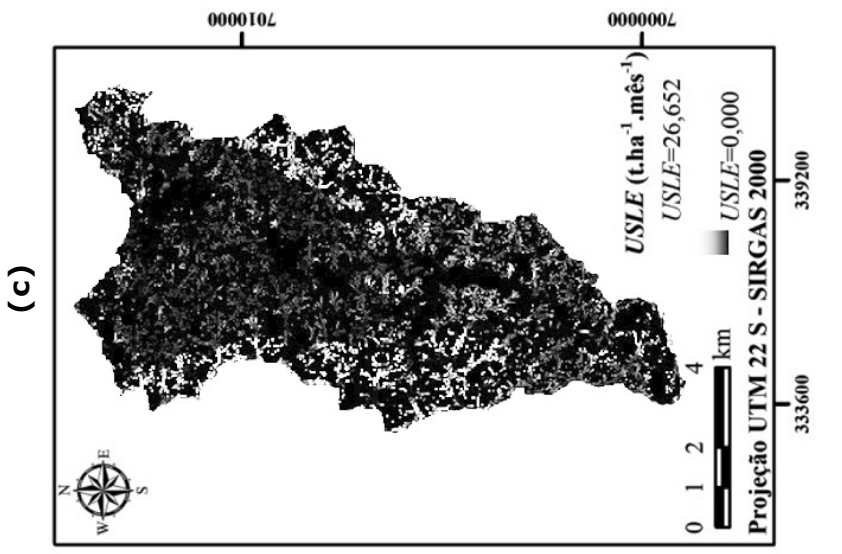

ㄸำ

ง ทับ

을

ฮั

홍 음

ข 20

ט

은 윰

ชั

는 음

은

ช

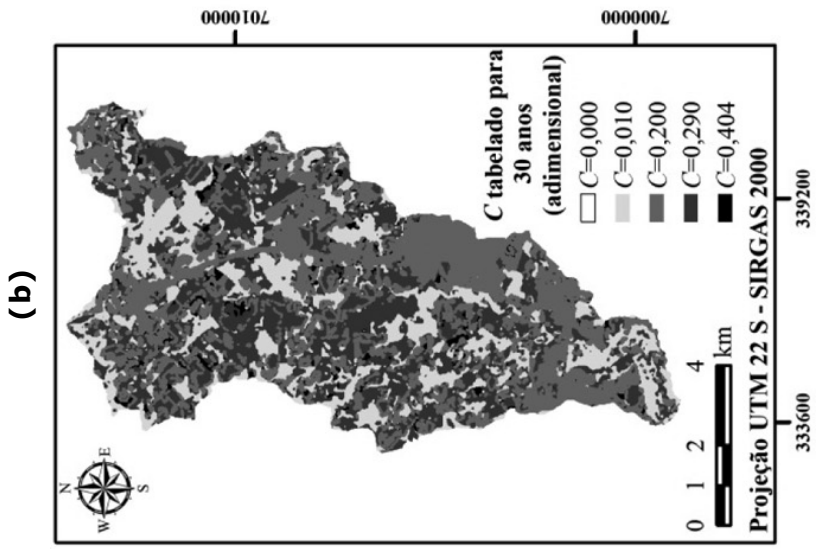

을 눈

즉 잉

흘 흥

ט

응

ס

으웅

은 듬

ㅇํㄱ ํํํ

ฮิ

วิ용

ดั

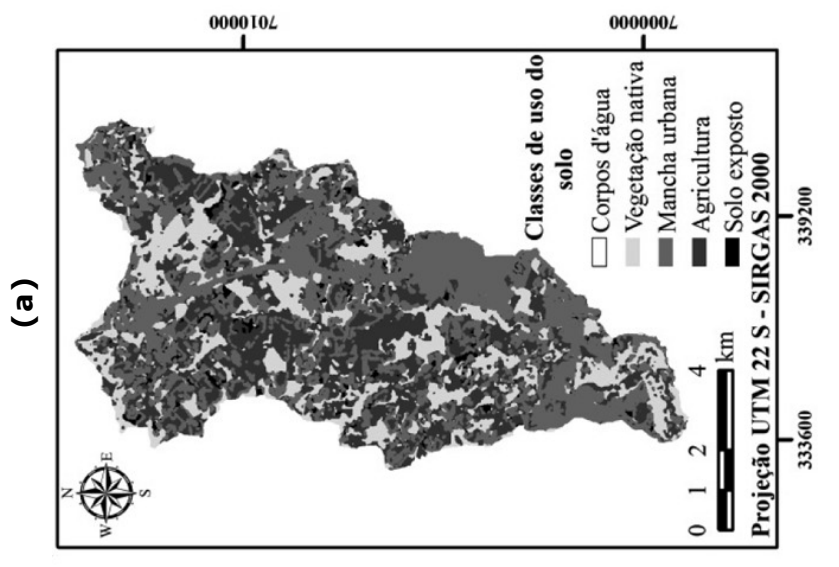

등

있 는

m

07

원

든

응

กิบ

는

$\sum 0$

人草 


\section{CONCLUSÕES}

Quando devidamente aplicados, os modelos empíricos de previsão de erosão podem ser considerados ferramentas adequadas para o estudo e análise de todos os fatores que interferem nos processos erosivos e também para auxílio em tomadas de decisões sobre a gestão do uso do solo. Apesar de apresentar certas limitações, a USLE permite não só a determinação da erosão do cenário atual como também possibilita a simulação de cenários futuros, como demonstrado também por Paes et al. (2014).

Este estudo demonstrou que as perdas de solo na bacia hidrográfica do Lajeado São José atualmente variam entre 0 e 30,166 t.ha ${ }^{-1} \cdot \mathrm{mês}^{-1}$, apresentando uma média de 3,88 t. ha ${ }^{-1}$.ano-1 pelo método de estimativa utilizando $C$ a partir do NDVI, enquanto pelo método utilizando $C$ tabelado as perdas variam entre 0 e 26,652 t.ha${ }^{1}$. ês $^{-1}$, apresentando uma média de 2,41 t. ha- ${ }^{-1}$. ano ${ }^{-1}$.

Com vistas à compreensão de processos erosivos, mediante a realização deste trabalho pode-se verificar que a dinâmica erosiva sofre influência principalmente por parte dos fatores $K$ e $L S$. Então, nas áreas onde tem-se ocorrência de valores mais altos desses fatores deve-se preservar a vegetação nativa e evitar o uso do solo para agricultura ou realizá-la com a adoção de práticas conservacionistas. No caso da bacia do Lajeado São José, estas áreas se concentram próximas ao divisor de águas.

Considerando-se a projeção da perda de solo para 30 anos, pode-se afirmar que esta chegará a uma taxa de 2,263 t.ha-1.ano-1. A redução de $6,2 \%$ se deve ao fato de que a bacia hidrográfica do Lajeado São José tem como principal uso do solo a agricultura, que na projeção de cenários será substituído pela urbanização. A diminuição da taxa de produção de sedimentos não pode ser vista como uma melhora para o desenvolvimento da bacia hidrográfica, por conta dos possíveis impactos na qualidade das águas decorrentes da urbanização.

Neste sentido, os resultados deste estudo apresentam-se de grande relevância, pois podem ser utilizados como ferramenta para a gestão de recursos hídricos e planejamento do uso e manejo dos solos da bacia. Em concordância com a conclusão de Robaina et al. (2002) e Lopes; Bias; Ribeiro (2009), neste trabalho também ficou evidente a importância do emprego de práticas conservacionistas no intuito de se manter ou reduzir a taxa de produção de sedimentos da bacia hidrográfica do Lajeado São José.

\section{REFERÊNCIAS}

ARNOLD, J.G.R.; MUTTIAH, R.S.; SRINIVASAN, R.; WILLIAMS, J. R. Large area hydrologic modeling and assessment. Part 1: Model development. Water Resources Association. v. 34. n. 1. p. 73-89, 1998.

BARBOSA, A.F.; MIOTO, C.L.; OLIVEIRA, E.F.; PARANHOS FILHO, A.C. Aplicação da Equação Universal de Perda do Solo (USLE) em softwares livres e gratuitos. Anuário do Instituto de Geociências - UFRJ. v. 38, n. 1, p.170-179, 2015.

BASSI, L. Estimativa da produção de sedimentos na bacia hidrográfica do Lajeado São José, Chapecó, Santa Catarina. 1990. 87 p. Dissertação (Mestrado em Hidrologia Aplicada) - Universidade Federal de Santa Maria, Curso de Pós Graduação em Agronomia, Santa Maria, 1990. 
BELLINASO, T.B.; PAIVA, J.B.D. Avaliação da produção de sedimentos em eventos chuvosos em uma pequena bacia hidrográfica semi-urbana de encosta. Revista Brasileira de Recursos Hídricos. v. 12, n. 4, p. 169-181, 2007.

BERTONI, J.; LOMBARDI NETO, F. Conservação do Solo. Piracicaba, SP: Editora Livroceres, 1985. 392p.

CARVALHO, N.O. Hidrossedimentologia prática. $2^{a}$ ed. Rio de Janeiro: Interciência, 2008. 599 p.

CHAPECÓ. Lei complementar no 541, de 26 de novembro de 2014. Aprova o Plano Diretor de Chapecó - PDC. Gabinete do Prefeito Municipal de Chapecó, Estado de Santa Catarina, em 26 de novembro de 2014.

COLLISCHONN, W.; TUCCI, C.E.M. Drenagem urbana e controle de erosão. In: SIMPÓSIO NACIONAL DE CONTROLE DA EROSÃO, 6., Presidente Prudente, 1998. Anais..., São Paulo: ABGE, 1998. p. 1-16.

CORRÊA, E.A; COUTO JUNIOR, A.A; PINTO, S.A.F. Espacialização temporal das perdas de solo em uma microbacia hidrográfica com predomínio de solos arenosos. Geografia, Rio Claro, v. 40, n. 1, p. 101-118, 2015.

CUNHA, C.M.L; MENDES, I.A.; SANCHEZ, M.C. A cartografia das perdas de solo por erosão e a propriedade rural: a busca de uma unidade espacial de mapeamento. Geografia (Rio Claro), v.24, n.2, p. 21-35, 1999.

DEBASTIANI, M.L. Estudo da evolução temporal do coeficiente de deflúvio no município de Chapecó-SC. 2015. 21 f. Trabalho de conclusão de curso de graduação (Graduação em Engenharia Ambiental) - Universidade Federal da Fronteira Sul, Chapecó, 2015.

EMBRAPA. Sistema Brasileiro de Classificação de Solos. 4. ed. Brasília, DF: Embrapa, 2014.

EMBRAPA. Solos do Estado de Santa Catarina. Boletim de Pesquisa e Desenvolvimento, n. 46. Rio de Janeiro, 2004.

FOSTER, G.R.; LAFLEN, J.M.; LANE, L.J.; NOWLIN, J.D.; YOUNG, R.A. Estimating erosion and sediment yield on field-sized areas. Transactions of the ASAE. v. 24, n. 5, p. 1253-1262, 1981.

GALDINO, S.; GREGO, C.R.; SILVA, J.S.V. Rainfall erosivity in the upper Paraguai river basin, Brazil. Geografia (Rio Claro), v. 40, n. especial, p. 119-129, 2015.

GÓMEZ, J.D.P. Estimativa de erosão pela Equação Universal de Perda de Solo (USLE) e transferência de sedimentos para todo território Brasileiro. São Paulo: Universidade de São Paulo - Escola Superior Agrícola de Agricultura "Luiz de Queiroz", 2012. 90 p. (Dissertação de Mestrado).

HUDSON, N.W. Soil conservation. $2^{a}$ ed. Ithaca: Cornell University Press. 1973. 320 p.

LOPES, J.A.A.; BIAS, E.S.; RIBEIRO, R.J.C. Aplicação da USLE para avaliação de perdas de solo no município de Águas Lindas de Goiás - GO. Geografia, Rio Claro, v. 34, n.2, p. 347-369, 2009.

MARQUES NETO, R.; VIADANA, A.G. Estudo da fragilidade morfodinâmica no sistema Atibaia-Jaguari em Americana (SP). Geografia, Rio Claro, v. 34, n. 1, p. 103-115, 2009.

MERRITT, W.S.; LETCHER, R.A.; JAKEMAN, A.J. A review of erosion and sediment transport models. Environmental Modelling \& Software. v. 18, n. 8-9, p. 761-799, 2003. 
MITASOVA, H.; HOFIERKA, J.; ZLOCHA, M.; IVERSON, L.R. Modeling topographic potential for erosion and deposition using GIS. International Journal of Geographical Information Systems. v. 10, n. 5, p. 629-641, 1995.

OLIVEIRA, A.M.M.; PINTO, S.A.F. Análise da dinâmica do uso da terra: o estudo da bacia hidrográfica do ribeirão São João (SP). Geografia, Rio Claro, v.28, n.2, p.197224, 2003.

PAES, F.S.; DUPAS, F.A.; SILVA, F.G.B.; PEREIRA, J.C.D. Áreas de preservação permanente e sua importância ambiental na prevenção da perda de solo por erosão em bacias hidrográficas. Geografia, Rio Claro, v. 39, n. 2, p. 351-362, 2014.

PEIXOTO, A.M.; SOUZA, J.S.I; TOLEDO, F.F; REICHARDT, K. MOLINA FILHO, J. Enciclopédia agrícola brasileira. v. 4. São Paulo: Editora da Universidade de São Paulo, 2002.

PINET, P.; SOURIAI, M. Continental erosion and large-scale relief. Tectonics. v. 7, n.3, p. 563-582, 1988.

RENARD, K.G.; FOSTER, G.R.; WEESIES, G.A.; MCCOOL, D.K.; YODER, D.C. Predicting soil erosion by water - a guide to conservation planning with the Revised Universal Soil Loss Equation (RUSLE). United States Department of Agriculture (USDA). Washington, DC. Agricultural Handbook, 1997. n. 703.407 p.

RIGHETTO, A.M. Hidrologia e recursos hídricos. São Carlos: EESC/USP, 1998. $840 \mathrm{p}$.

RISSO, A.; SORIANO, B.M.A.; PADOVANI, C.R.; MELO, E.C.; VIEIRA, L.M.; ALMEIDA JUNIOR, N.; GALDINO, S. Erosão potencial laminar hídrica na bacia do Alto Taquari. Revista Brasileira de Recursos Hídricos. v. 9, n. 2. p. 125-133, 2004.

ROBAINA, L.E.; NETO, S.F.; PAULA, P.M.; PEREIRA, V.P. Processo erosivo acelerado no RS: voçorocamento no município de Cacequi. Geografia, Rio Claro, v.27, n.2, p.109120, 2002.

SANTA CATARINA. Atlas escolar de Santa Catarina. Secretaria de Estado e Coordenação Geral e Planejamento, Subsecretaria de Estudos Geográficos e Estatísticos. Rio de Janeiro, Aerofoto Cruzeiro, 1991.

SCHAAP, M.G.; LEIJ, F.J.; van GENUCHTEN, M.Th. ROSETTA: a computer program for estimating soil hydraulic properties with hierarchical pedotransfer functions. Journal of Hydrology, v.251, n.3-4, p.163-176, 2001.

SCHICK, J.; BERTOL, I.; COGO, N.P.; GONZÁLEZ, A.P. Erosividade das chuvas de Lages, Santa Catarina. Revista Brasileira de Ciência do Solo. v. 38, p. 18901905, 2014.

SILVA, A.M. Potencial natural de erosão no município de Sorocaba, São Paulo, Brasil. Revista Internacional de Desastres Naturales, Accidentes e Infraestructura Civil. v. 8, n. 1, p. 5-13, 2008.

SUMMERFIELD, M.A.; HULTON, N.J. Natural controls of fluvial denudation rates in major world drainage basins. Journal of Geophysical Research. v. 99, n. B7, 1994, p. 13871-13883.

THOMAZ, E.L. Processo hidrológico superficial e uso da terra em Guarapuava-PR: mensurações em parcelas pequenas. Geografia, Rio Claro, v. 32, n.1, p. 89-106, 2007.

TOMBUŞ, F.E.; YÜKSEL, M.; ŞAHİN, M.; OZULU, İ.M.; COŞAR, M. Assessment of soil erosion based on the method USLE, Corum Province example. FIG working week, Knowing to manage the territory, protect the environment, evaluate the cultural heritage. Rome, Italy. 2012. p. 1-11. 
TUCCI, C. E. M. Hidrologia: ciência e aplicação. 2ed. Porto Alegre: ABRH, 1993. 943 p.

TUCKER, C.J. Red and photographic infrared linear combinations for monitoring vegetation. Remote Sensing Environment. v. 8, n. 2, p. 127-150, 1979.

USDA. From the surface down: an introduction to soil surveys for agronomic use. 2 ed. Washington, 2010. 34 p.

VALVASSORI, M.L.; BACK, A.J. Avaliação do potencial erosivo das chuvas em Urussanga, SC, no período de 1980 a 2012. Revista Brasileira de Ciência do Solo. v. 38, n. 3, p. 1011-1019, 2014.

van der KNIJFF, J.M.; JONES, R.J.A.; MONTANARELLA, L. Soil erosion risk assessment in Europe. Ispra: European Soil Bureau. Joint Research Centre. 2000. 38 p.

VERLENGIA, F.; GARGANTINI, H. Determinação de matéria orgânica em solos- estudo comparativo de métodos. Bragantia. Boletim científico do Instituto Agronômico do Estado de São Paulo. v. 27, n.3, p. 257-265, 1968.

VIEIRA, V.F. Estimativa de perdas de solo por erosão hídrica em uma sub-bacia hidrográfica. Geografia, Londrina. v. 17, n.1, p. 73-81, 2008.

WALTRICK, P.C.; MACHADO, M.A.M.; DIECKOW, J.; OLIVEIRA, D. Estimativa da erosividade de chuvas no estado do Paraná pelo método da pluviometria: atualização com dados de 1986 a 2008. Revista Brasileira de Ciência do solo. v. 39, n. 1, p. 256-267, 2015.

WILLIAMS, J.R. Sediment-yield prediction with Universal Equation using runoff energy factor. In: Sediment yield Workshop, 1., Oxford, Mississippi, 1975. Proceedings..., Oxford, Mississippi: USDA Sedimentation Laboratory, 1975. p. 244-252.

WISCHMEIER, W.H. A rainfall erosion index for a universal soil-loss equation. Soil Science Society of America Journal. v. 23, n. 3. p. 246-249, 1959.

WISCHMEIER, W.H.; SMITH, D.D. Predicting rainfall erosion losses: a guide to conservation planning. USDA, Agriculture Handbook no 537 Dep. Agric., 1978. 67p.

YOUNG, R.A.; ONSTAD, C.A.; BOSCH, D.D.; ANDERSON, W.P. AGNPS: A nonpointsource pollution model for evaluating agricultural watersheds. Journal of Soil and Water Conservation, v. 44, n. 2, p. 168-173, 1989.

Recebido em fevereiro de 2017 Aceito em agosto de 2017 
